\title{
Vernalization in a Greenhouse Promotes and Synchronizes Flowering of Osteospermum ecklonis Norl.
}

\author{
Ayumi Suzuki ${ }^{1}$ and James D. Metzger ${ }^{2}$ \\ Department of Horticulture and Crop Science, The Ohio State University, \\ 2001 Fyffe Court, Columbus, OH 43210-1086
}

Additional index words. flower induction, stem elongation, temperature, stem number, flower number

\begin{abstract}
The effect of cool temperature treatments on flowering of Osteospermum ecklonis Norl. cv. Nairobi was evaluated. Plants vernalized at temperatures from 4 to $15{ }^{\circ} \mathrm{C}$ for 4 to 6 weeks exhibited increased flower numbers, more synchronized flower development among individual plants, and reduced forcing times. Part of the increased flower number observed in the vernalized plants could be attributed to a small increase in branch numbers from 2 to 3. However, a longer period of vernalization slowed flower development, and therefore increased overall production times. Vernalization also reduced stem growth, primarily through a reduction in the number of nodes produced by each branch.
\end{abstract}

Osteospermum ecklonis, a member of the Asteraceae family, is native to South Africa (Norlindh, 1977). Although considered a weed in its native region, osteospermum has been bred and developed as an ornamental crop in Europe (Olsen and Anderson, 1995). The species has been introduced in North America as a potted flower.

The plant has alternately arranged oblong leaves, $\approx 10 \mathrm{~cm}$ long, which are coarsely serrate-dentate and glandular-pubescent. The flower is a composite capitulum with overlapping ray floret petals (Huxley et al., 1992). Flower color varies among cultivars; in the cultivar 'Nairobi', the subject of this report, the adaxial side of the petal is white and the abaxial side is bluish-purple with stripes. The color of the disc florets is blue, and the dehisced pollen is bright yellow. The flower is $\approx 60 \mathrm{~mm}$ in diameter.

Little cultural information is available for growers interested in producing $O$. ecklonis. One of the limitations in osteospermum production is sparse and sporadic flower formation. Understanding how environmental factors such as photoperiod or temperature affect flowering is important for growers. Therefore, the primary objective of this work was to determine whether flowering is controllable for commercial production schedules.

Received for publication 9 Sept. 1999. Accepted for publication 20 Sept. 2000. This paper is based on a portion of thesis submitted by A. Suzuki in partial fulfillment for the requirements for the MS degree in horticulture. Research supported in part by the D.C. Kiplinger Endowment for Floriculture. Use of trade names does not imply endorsement of the products named or criticism of similar ones not named. The cost of publishing this paper was defrayed in part by the payment of page charges. Under postal regulations, this paper therefore must be hereby marked advertisement solely to indicate this fact.

${ }^{1}$ Graduate Research Assistant.

${ }^{2}$ Professor. To whom reprint requests should be addressed.. E-mail address: metzger.72@osu.edu
In preliminary work, we found that altering the photoperiod had little effect on flowering. However, there is at least one report indicating that $O$. ecklonis responds positively to low temperature treatments upon flowering. For their studies on the effects of various growth regulators on $O$. ecklonis, Olsen and Andersen (1995) employed a 3 week vernalization treatment at $8{ }^{\circ} \mathrm{C}$ to promote flowering, though no details were provided on the effectiveness of the treatments. In addition, research on the closely related species, $O$. jucundum Norl., showed that vernalization at $12{ }^{\circ} \mathrm{C}$ promoted flowering (Pearson et al., 1995).

Considering this information, vernalization may be the most influential factor affecting flowering in O. ecklonis, although optimum temperatures and duration have not been determined. For many cold-requiring species, temperatures of 0 to $15^{\circ} \mathrm{C}$ are effective for vernalization with typically broad optimal ranges that vary slightly in different species (Bernier et al., 1981; Lang, 1965; Metzger, 1995; Wiebe, 1990). For example, optimum vernalizing temperatures are 2 to $7^{\circ} \mathrm{C}$ for Lilium longiflorum Thunb. (Easter lilies) (Rees, 1992), 10 to $13^{\circ} \mathrm{C}$ for Olea europaea L. (olive) (Hackett and Hartmann, 1967), and 0 to $10^{\circ} \mathrm{C}$ for Thlaspi arvense $\mathrm{L}$. (field pennycress) (Metzger, 1995). The effects of vernalization gradually decline when the temperature exceeds the optimum range. Previous growth chamber studies, in which O.ecklonis plants were vernalized at $5,10,15,20$, and 25 ${ }^{\circ} \mathrm{C}$ for various periods of time, showed that upper limit for effective vernalization is between 15 and $20{ }^{\circ} \mathrm{C}$, although maximum flower promotion was observed at 5 and 10 ${ }^{\circ} \mathrm{C}$; (Suzuki, 1997). However, the use of growth chambers for vernalization treatments is not practical under commercial settings, and so we determined if $O$. ecklonis could be successfully vernalized under simulated commercial greenhouse conditions.
Expt. 1. Effects of vernalization. Rooted cuttings of $O$. ecklonis 'Nairobi' were obtained from a commercial producer on 3 Oct. 1996. The individual cuttings were transplanted into standard $16.5-\mathrm{cm}$ diameter pots containing soilless media (Metro-Mix 360; ScottsSierra Horticulture Products Co., Marysville, Ohio). All plants were placed in a greenhouse with daytime set-point temperature of $24{ }^{\circ} \mathrm{C}$ from 0600 to $2000 \mathrm{HR}$ and nighttime set-point temperature of $18{ }^{\circ} \mathrm{C}$ for the remaining $10 \mathrm{~h}$. On 3 Nov. 1996, all plants were pinched $5 \mathrm{~cm}$ above the surface of the medium. Thirty plants were vernalized in a greenhouse with a set point temperature of $4{ }^{\circ} \mathrm{C}$. The temperature range in the cool greenhouse was 4 to $10^{\circ} \mathrm{C}$, as monitored by an Oglevee Computer System (Connellsville, $\mathrm{Pa}$.), and is within the optimum temperature range for vernalization in many species (Lang, 1965; Metzger, 1995; Wiebe, 1990). The other 30 plants remained in the original greenhouse as controls; the temperature in the warm greenhouse did not vary more than $\pm 2{ }^{\circ} \mathrm{C}$ from the set point temperatures. Plants were irrigated as necessary and fertilized with a complete fertilizer $(20 \mathrm{~N}-8.6 \mathrm{P}-$ $16.6 \mathrm{~K})$ at a concentration of $150 \mathrm{mg} \cdot \mathrm{L}^{-1}$ of $\mathrm{N}$ (Scotts-Sierra Horticulture Products Co., Marysville, Ohio) three times a week for the duration of the experiment. A $16 \mathrm{~h}$ photoperiod was maintained in both greenhouses by providing supplemental light [80-100 $\mu \mathrm{mol} \cdot \mathrm{m}^{-2} \cdot \mathrm{s}^{-1}$ photosynthetically active radiation $(P A R)$ at bench level] from GE Lucalox high-pressure sodium lamps (General Electric Co., Cleveland) from 0700 to $1000 \mathrm{HR}$ and 1600 to $2300 \mathrm{HR}$. The experiment was concluded on 15 Apr. 1997.

Expt. 2. Effects of duration of vernalization. Rooted cuttings of O. ecklonis 'Nairobi' were obtained from the commercial producer on 3 Feb. 1997 and planted on the same day using the procedures described in Expt. 1. The plants were placed in the warm (control) greenhouse as described for Expt. 1. After four weeks, plants were pinched to $5 \mathrm{~cm}$ above the surface of the root medium. Ten plants remained in the same greenhouse as the warm control, while the other plants were placed in a cool greenhouse with a set-point temperature of $8{ }^{\circ} \mathrm{C}$ for vernalization. Groups of ten plants each were vernalized in the cool greenhouse for 2, 4, or 6 weeks and returned to the warm greenhouse. Another group of ten plants remained in the cool greenhouse for an additional 8 weeks until the experiment was terminated on 15 June. During the first 9 weeks of vernalization, the temperature of the greenhouse fluctuated in the range of 6 to $15^{\circ} \mathrm{C}$. However, the frequency and duration of temperatures exceeding $15{ }^{\circ} \mathrm{C}$ increased during the remaining 6 weeks of the experiment. Plants were irrigated as necessary and fertilized as described in Expt. 1. The concentration of the fertilizer was increased to $200 \mathrm{mg} \cdot \mathrm{L}^{-1}$ of $\mathrm{N}$ in May.

Assessment of flowering. The flowering response was assessed by three factors: the time from planting of the rooted cuttings until 
the appearance of the first open flower on individual plants (DF), the total number of flowers produced by each plant (FN), and the number of nodes (NN) on each stem. Also the number of stems (TSN) produced by each plant was determined and their average length (SL) calculated. The data were subjected to one-way analysis of variance (ANOVA) using the Minitab statistical program (Minitab, State College, Pa.). Means were separated by Tukey's pairwise comparison (Zar, 1974) at a $P=0.05$ confidence level.

\section{Results and Discussion}

Expt. 1. Effects of vernalization. Control plants, under warm conditions, remained mostly vegetative throughout the experiment with the sporadic appearance of a few flowers. They produced an average of 0.5 flowers per plant, although 10 of the 30 plants did not flower at all (Table 1). Flowering in plants in the cool greenhouse was promoted, as evidenced by the large increase in the FN. Vernalized plants produced an average of three flowers per stem, with seven being the highest number recorded. Along with increased FN, flowering was more synchronized in the vernalized plants, as indicated by the smaller standard deviations relative to the control (Table 1). Indeed, all of the vernalized plants flowered within a two-week period compared with $70 \mathrm{~d}$ for the control plants. Nearly $87 \%$ of the vernalized plants produced at least one flower over a $4 \mathrm{~d}$ period, 131 to $134 \mathrm{~d}$ after transplanting. Therefore, vernalization induced more uniform flowering and a much larger number of flowers.

Vernalization also promoted the growth of lateral branches; there was a small but significant increase in the average TSN in the vernalized plants (Table 1), and some of the increase in FN can be attributed to this. Given an average of three flowers per stem in the vernal- ized plants, roughly $25 \%$ of the increase in FN can be attributed to increased branching.

Stems of vernalized plants were $\approx 40 \%$ shorter than those of control plants (Table 1). Most of this reduction in SL was due to the production of $65 \%$ fewer nodes. Presumably the reduction in $\mathrm{NN}$ in the vernalized plants was the result of earlier flower initiation since no additional leaves are produced after flower primordia are initiated in determinant plants.

Expt.2. Effect of duration of vernalization. As in most cold-requiring species (Lang, 1965; Metzger, 1995; Wiebe, 1990), there was a quantitative relationship between the length of vernalization and the flowering response (Table $2)$. The FN increased with duration of vernalization, reaching a maximum after 6 weeks of vernalization. However, 2 weeks of vernalization did not significantly increase FN, indicating that this osteospermum cultivar has a minimum vernalization requirement between 2 and 4 weeks. In addition, maximum flower induction was achieved with 6 weeks of vernalization; no increase in flower number was observed with a longer treatment (Table 2), even though greenhouse temperatures were maintained in the effective range for vernalization of O. ecklonis (Suzuki, 1997) for an additional 3 weeks. However, this maximum level of floral induction was nearly achieved by 4 weeks of vernalization, as evidenced by the much larger increase in FN observed when vernalization was extended from 2 to 4 weeks (5.7-fold) compared with that obtained by increasing the vernalization period from 4 to 6 weeks (1.3-fold). As was the case in Expt. 1, part of the increase in FN observed in vernalized plants is the result of the greater number of stems produced (Table 2).

The number of nodes produced on individual branches decreased with duration of vernalization. The maximum reduction in $\mathrm{NN}$ was observed after 4 or more weeks, while the
2 week treatment resulted in an intermediate effect (Table 2). Leaf production ceases when flower primordia are initiated in determinate plants; therefore, the number of nodes can be used as a measure of the relative time of flower initiation in the apical meristem (Bernier et al., 1984). Although two weeks of vernalization had no effect on FN, both NN and DF were significantly reduced. This suggests that at least some of the processes required for floral induction had been completed by this time. Therefore, the initiation of flower primordia must have begun between 2 and 4 weeks after the cold treatments began because vernalization treatments longer than 4 weeks did not further reduce $\mathrm{NN}$.

The greatest reductions in average DF were observed in the 2 and 4 week vernalization treatments (Table 2). In these treatments, flowering occurred $\approx 14$ weeks after transplanting, while plants subjected to 6 weeks of vernalization flowered after 15 weeks. The control plants and plants that were maintained in the cool greenhouse for 15 weeks flowered in 17 weeks, and these results are consistent with those obtained in Expt.1. Many flower buds were visible at the end of the experiment on the plants that were continuously vernalized (data not shown), indicating that extending the duration of the cold treatment for periods longer than 4 weeks delayed flower development, resulting in increased production time. Thus, while extending vernalization may result in larger FN, this benefit must be balanced against the increased time required for flower opening (Table 2). However, increasing the duration of vernalization from 2 to 6 weeks progressively reduced forcing times, i.e., the number of days from the end of vernalization to the appearance of the first open flower (Table 2).

Consistent with the results in Expt. 1, vernalization synchronized flowering among individual plants, as indicated by the reduction

Table 1. The effect of vernalization on flowering and plant architecture of Osteospermum ecklonis cv. Nairobi. Rooted cuttings were planted 3 Oct. 1996 and placed in a greenhouse with day and night set point temperatures at 24 and $18^{\circ} \mathrm{C}$, respectively. After 4 weeks, half the plants were moved to a cool greenhouse with a set point temperature of $4{ }^{\circ} \mathrm{C}$ for vernalization; the other plants remained in the warm greenhouse as controls. The experiment was concluded $15 \mathrm{Apr}$. 1997. Values represent the means of 30 plants \pm sD. Numbers in parentheses represent the means as percentages of control values.

\begin{tabular}{lccccc}
\hline \hline Treatment & Total flower no. & Days to first open flower & Stem length $(\mathrm{mm})$ & Total stem no. & Total no. of nodes \\
\hline Control & $0.5 \pm 0.9$ & $142.0 \pm 34.2$ & $464.6 \pm 21.2(100)$ & $7.7 \pm 1.2$ & $48.4 \pm 18.5(100)$ \\
Vernalization & $32.2 \pm 7.4^{*}$ & $135.2 \pm 7.9$ & $270.9 \pm 19.4^{*}(58)$ & $10.9 \pm 1.6^{*}$ & $17.6 \pm 0.8^{*}(36)$ \\
\hline
\end{tabular}

"Significantly different from control value at $P=0.05$

Table 2. The effects of different durations of vernalization on flowering and plant architecture in Osteospermum ecklonis cv. Naroibi. Rooted cuttings were planted $3 \mathrm{Feb} .1997$ and placed in a greenhouse with day and night set point temperatures of 24 and $18^{\circ} \mathrm{C}$, respectively. After 4 weeks, 40 plants were moved to a cool greenhouse with a set point temperature of $8{ }^{\circ} \mathrm{C}$ for vernalization. At 2 , 4 , and 6 week intervals, a group of 10 plants were returned to the greenhouse; a group of 10 plants remained in the cool greenhouse until the experiment was concluded on 15 June 1997. The values represent the means of 10 plants \pm SD. Numbers in parentheses represent the means as percentages of the control values.

\begin{tabular}{|c|c|c|c|c|c|c|}
\hline \multirow{2}{*}{$\begin{array}{l}\text { Vernalization } \\
\text { period (wk) }\end{array}$} & \multicolumn{3}{|c|}{ Total no. of: } & \multirow{2}{*}{$\begin{array}{l}\text { Days to first } \\
\text { open flower }\end{array}$} & \multirow{2}{*}{$\begin{array}{l}\text { Forcing } \\
\text { time }^{\mathrm{z}}(\mathrm{d})\end{array}$} & \multirow[b]{2}{*}{ Stem length $(\mathrm{mm})$} \\
\hline & Flowers & Stems & Nodes & & & \\
\hline$\overline{0 \text { (Control) }}$ & $1.4 \pm 0.8 \mathrm{c}^{\mathrm{y}}$ & $11.1 \pm 1.6 \mathrm{~b}$ & $53.2 \pm 5.3 \mathrm{a}(100)$ & $121.2 \pm 14.4 \mathrm{a}$ & --- & $436.2 \pm 36.1 \mathrm{a}(100)$ \\
\hline 2 & $7.2 \pm 6.6 \mathrm{c}$ & $12.8 \pm 1.5 \mathrm{ab}$ & $26.8 \pm 6.2 \mathrm{~b}(50)$ & $295.1 \pm 7.9 \mathrm{~d}$ & 53 & $298.4 \pm 55.1 \mathrm{bc}(68)$ \\
\hline 4 & $41.3 \pm 4.5 b$ & $13.6 \pm 1.5 \mathrm{a}$ & $21.8 \pm 3.0 \mathrm{c}(41)$ & $98.1 \pm 2.6 \mathrm{c}$ & 42 & $281.6 \pm 27.8 \mathrm{~cd}(65)$ \\
\hline 6 & $54.0 \pm 4.1 \mathrm{a}$ & $12.6 \pm 1.3 \mathrm{ab}$ & $21.7 \pm 3.2 \mathrm{c}(41)$ & $105.8 \pm 3.0 \mathrm{~b}$ & 36 & $305.1 \pm 29.8$ b (70) \\
\hline 15 & $56.8 \pm 7.2 \mathrm{a}$ & $14.0 \pm 0.9 \mathrm{a}$ & $21.6 \pm 3.2 \mathrm{c}(41)$ & $120.1 \pm 3.1 \mathrm{a}$ & --- & $267.4 \pm 24.6 \mathrm{~d}(61)$ \\
\hline
\end{tabular}

${ }^{2}$ Time from the end of vernalization to the first open flower.

y Mean separation within columns by Tukey's pairwise comparison, $P<0.05$. 
in the standard deviations of DF. However, the maximum amount of synchrony was achieved with 4 weeks of cold; no further increases were observed with longer treatments (Table 2).

As observed in Expt. 1, vernalization reduced stem length primarily as a result of cessation of vegetative growth when the plants were induced to flower (Table 2). However, not all of the reduction in stem length can be attributed to the reduced number of nodes, since vernalization reduced $\mathrm{NN}$ proportionally more than SL (Table 2). Moreover, while NN was not significantly different for 4,6 , or 16 weeks of vernalization, the average stem length of the plants vernalized for 6 weeks was longer for the other two treatments (Table 2). This suggests that other factors also affected stem length through effects on internode elongation. Variations in environmental factors, such as light intensity or temperature, during the period of internode elongation might account for differences among these three treatments.

Osteospermum has a creeping growth habit with a tendency to quickly overgrow standard pots, and therefore some kind of growth con- trol is necessary to produce a saleable crop. However, we showed that a 4- or 6-week vernalization treatment reduced stem lengths by $30 \%$ to $35 \%$, resulting in a compact, attractive plant without resorting to the use of chemical growth regulators. Thus, with the proper integration of a vernalization treatment into the production schedule, reducing the need for additional operations for growth regulation may be possible.

\section{Literature Cited}

Bernier, G., J.M. Kinet, and R. M. Sachs. 1981. The physiology of flowering. vol. 1. CRC Press, Boca Raton, Fla.

Hackett, W.P. and H.T. Hartmann. 1967. The influence of temperature in floral initiation in the olive. Physiol. Plant. 20:430-436.

Huxley, A., M. Griffiths, and M. Levy. 1992. Osteospermum, p. 416-417. The New Royal Horticulture Society Dictionary of Gardening, vol. 3. Macmillan, London.

Lang, A. 1965. Physiology of flower initiation, p. 1380-1536. In: W. Ruhlans (ed.). Encyclopedia of Plant Physiology. vol. 15. Springer-Verlag, Berlin.
Metzger, J. 1995. A physiological comparison of vernalization and the dormancy chilling requirement, p. 147-156. In: G.A. Lang (ed.) Plant dormancy: Physiology, biochemistry and molecular biology. CAB Intl., London.

Norlindh, T. 1977. Calenduleae-Systematic review, p. 961-987. In: V.H. Heywood, J.B. Harborne and B.L. Turner (eds.). The Biology and chemistry of the compositae, vol. 2. Academic, London.

Olsen, W. and A. Andersen. 1995. The influence of five growth retardants on growth and post production qualities of Osteospermum ecklonis cv. 'Calypso'. Scientia Hort. 62:225-235

Pearson, S.A., P. Hadley, and H.M. Lichener. 1995. The effect of photoperiod and temperature on reproductive development of cape daisy (Osteospermum jucundum cv. 'Pink Whirls'). Scientia Hort. 62:225-235

Rees, R. 1992. Ornamental Bulbs, Corms and Tubers. CAB Intl., London.

Suzuki, A. 1997. Production Management for Potted Osteospermum ecklonis. MS Thesis, Dept. Hort. and Crop Sci., The Ohio State Univ. Columbus.

Wiebe, H.-J. 1990. Vernalization of vegetable crops-A review. Acta Hort. 267:323-328.

Zar, J.H. 1974. Biostatistical analysis. Prentice Hall, Englewood Cliffs, N.J. 